\title{
Statins May Increase Intracerebral Hemorrhage Volume
}

\author{
Geneviève Ricard, Marie-Pierre Garant, Nathalie Carrier, Nancy Leblanc, \\ Jean-Martin Boulanger
}

\begin{abstract}
Background: Some studies have suggested an association between hypocholesterolemia and intracerebral hemorrhage (ICH). In the SPARCL trial, statin use increased ICH risk. We tested the hypothesis that use of statins affects the volume of spontaneous ICH and contributes to the progression of ICH volume between baseline and follow-up CT scans. Methods: Consecutive cases of spontaneous ICH were reviewed. Secondary causes were excluded. We measured ICH volume on the baseline and follow-up CT scans using the $\mathrm{AxBxC} / 2$ method. Multivariate analysis and logistic regression modeling were used. The primary outcome was the ICH volume on the baseline CT scan. Secondary outcomes included volume variation between the baseline and the first follow up CT scans and death. Results: Of 303 subjects, 71 were taking a statin at the time of the ICH (23\%). Statin users were significantly more likely to be younger, to have co-morbidities and take anticoagulant or anti-platelet medication. They also had a higher baseline ICH volume than non-statin users (median 31.2 [10,82.1] ml vs 16 [4,43.8] ml; $\mathrm{p}=0.006$ ). Adjusting for possible confounders, statins remained associated with an increased $\mathrm{ICH}$ volume $(\mathrm{p}=0.007)$. There was a significant mean $\mathrm{ICH}$ volume progression between the first and second $\mathrm{CT}$ scans in statin users $(+10.8 \mathrm{vs}+0.9 \mathrm{ml} ; \mathrm{p}=0.03 ; 95 \% \mathrm{CI}$ : $[-1,+22.6][-2.5,+4.3])$. No difference in mortality was seen between the two groups . Conclusion: Treatment with HMG-CoA reductase inhibitors may be a risk factor for increased ICH volume in spontaneous brain hemorrhages and could contribute to hemorrhage's volume progression.
\end{abstract}

RÉSUMÉ: Les statines pourraient augmenter le volume de l'hémorragie intracérébrale. Contexte : Selon certaines études, il existerait une association entre l'hypocholestérolémie et l'hémorragie intracérébrale (HIC). Dans l'essai clinique SPARCL, l'utilisation d'une statine augmentait le risque d'HIC. Nous avons vérifié l'hypothèse selon laquelle l'utilisation de statines influence le volume de l'HIC spontanée et contribue à la progression du volume de l'HIC à la tomodensitométrie cérébrale initiale et de suivi. Méthodes : Des cas consécutifs d'HIC spontanée ont été révisés. Les causes secondaires ont été exclues. Nous avons mesuré le volume de l'HIC à la tomodensitométrie initiale et à celle de suivi au moyen de la formule AxBxC/2. L'analyse multivariée et la régression logistique ont été utilisées pour l'analyse des données. L'issue primaire était le volume de l'HIC à la tomodensitométrie initiale. Les issues secondaires étaient la variation du volume entre la tomodensitométrie initiale et la première effectuée au cours du suivi et le décès. Résultats : Soixante et onze des 303 sujets prenaient une statine au moment de l'HIC (23\%). Les sujets qui prenaient une statine avaient une plus forte probabilité d'être plus jeunes, d'avoir des comorbidités et de prendre des anticoagulants ou des antiplaquettaires. Ils avaient également un volume initial d'HIC plus grand que ceux qui ne prenaient pas de statines (médiane $31,2[10,82,1] \mathrm{ml}$ versus $16[4,43,8] \mathrm{ml} ; \mathrm{p}=0,006$ ). Après ajustement pour les variables confondantes possibles, les statines demeuraient associées à un volume plus grand d'HIC (p = 0,007). Il y avait une progression significative du volume de l'HIC entre la première et la seconde tomodensitométrie chez les sujets qui prenaient une statine (+10,8 versus $+0,9 \mathrm{ml} ; \mathrm{p}=0,03$; IC à 95\% : -1 à $+22,6$ et $-2,5$ à $+4,3$ respectivement). Nous n'avons pas observé de différence de mortalité entre les deux groupes. Conclusion : Le traitement par les inhibiteurs de l'HMG-CoA réductase pourrait constituer un facteur de risque d'un plus grand volume d'HIC dans les hémorragies cérébrales spontanées et pourrait contribuer à la progression du volume de l'hémorragie.

Can. J. Neurol. Sci. 2010; 37: 791-796

Several epidemiological studies have demonstrated an association between hypocholesterolemia and the incidence of intracerebral hemorrhage $(\mathrm{ICH}) .{ }^{1-3}$ HMG-CoA reductase inhibitors (statin) may theoretically increase the risk of cerebral hemorrhage, given its cholesterol-lowering effect. In addition, statins have been associated with decreased platelet function via direct influence on platelet membrane and inhibition of PAR-1, which is a cell-bound protein that links platelet activation. ${ }^{4-6}$

An exploratory analysis of the Stroke Prevention by Aggressive Reduction in Cholesterol Levels (SPARCL) trial found that statins overall effect included an increase in the number of treated patients having hemorrhagic stroke (n 55 for active treatment vs $\mathrm{n} 33$ for placebo) with an unadjusted HR 1.68. ${ }^{7}$ The Heart Protection Study (HPS) earlier described this effect in a subgroup of patients with a history of cerebrovascular disease. ${ }^{8}$ A meta-analysis of four studies including patients with a history of cerebrovascular disease was conducted recently to confirm these data. ${ }^{9}$ The conclusion was that the beneficial effect of statins was partly offset by an increased risk of $\mathrm{ICH}$.

From the Étienne-Le Bel Clinical Research Center (MPG, NC), Centre Hospitalier (GR, MPG, NC,) Universitaire de Sherbrooke CHUS; Department of Neurology (GR, JMB), Hôpital Charles Lemoyne (NL, JMB), University of Sherbrooke, Sherbrooke, Quebec, Canada.

Received April 5, 2010. Final Revisions Submitted June 24, 2010.

Correspondence to: Jean-Martin Boulanger, Neuro Rive-Sud Clinic, 4896 Boulevard Taschereau \#250, Greenfield Park, Quebec, J4V 2J2, Canada. 
In contrast, a meta-analysis of previous statin therapy trials carried out predominately with patients with coronary heart disease - found no relationship between statin treatment and the risk of hemorrhagic stroke. ${ }^{10}$

As a result of these observations, controversy remains about HMG-CoA reductase therapy and its association with $\mathrm{ICH}$. Moreover, it is not known whether statins augment the propensity for bleeding and generate larger hematomas. Therefore, we tested the hypothesis that statin use affects the volume of spontaneous ICH and promotes hematoma expansion.

\section{METHODS}

\section{Study Subjects}

This retrospective observational study was conducted in two affiliated medical centers (Charles-LeMoyne Hospital, Centre Hospitalier, Universitaire de Sherbrooke). All cases $\geq 18$ years old of spontaneous intracerebral hemorrhage between January 2002 and October 2007 were reviewed. Hematomas were radiologically proven by CT scan. Secondary causes such as arteriovenous malformations, brain trauma, tumor, drugs and aneurysms were excluded. Other exclusion criteria were hemorrhagic infarction, thrombolytic treatment complication of ischemic stroke, and blood dyscrasias.

\section{Measurements}

Clinical informations-including past medical history, baseline modified Rankin score and medication use-were abstracted from medical records. Patients were defined as anticoagulated if they were taking warfarin, fractionated or low molecular weight heparin. The baseline international normalized ratio (INR) and platelet value upon medical presentation were recorded. Outcomes were adjusted for anticoagulation. Lowdensity lipoprotein (LDL) cholesterol levels were noted when available.

The Glasgow Coma Scale was noted and a validated modified National Institutes of Health Stroke Scale (mNIHSS) score was estimated from chart review. ${ }^{11}$

\section{Imaging}

The ABC/2 method was used for ICH volume measurement on baseline and follow up CT scans when available. ${ }^{12}$ All CT were reviewed by a stroke neurologist (JMB) or a neurology resident (GR). The volume variation between the baseline and the first follow up CT scans was also measured. Twenty five CT scans were reviewed by both JMB and GR to insure the interreliability in $\mathrm{ICH}$ volume measurement. The location of each intracerebral hemorrhage was categorized as deep or infratentorial (basal ganglia, thalamus, internal capsule, deep periventricular white matter, cerebellum, and brainstem) or lobar (cortex and subcortical white matter). The presence of ventricular extension was also assessed. Patients with craniotomy were excluded from calculations of hematoma variation volume because of potentially confounding bias.

\section{Outcomes}

The primary outcome was $\mathrm{ICH}$ volume on the baseline CT scan using the $\mathrm{ABC} / 2$ method. ${ }^{12}$ Secondary outcomes included volume variation between baseline and first follow up CT scans and death from any causes during hospitalization.

\section{Data Analysis}

Patients were dichotomized as using or not using statin. Univariate analyses were used to examine differences between the two groups and to determine whether statin influenced initial and follow up median ICH volume. Fisher Exact and Chi-Square tests were used for nominal variables and Student t-test for continuous normal variables. Lin's concordance correlation coefficient was used for assessment of the inter-rater reliability in $\mathrm{ICH}$ volume measurement. Because of the asymmetry of ICH volume's distribution, we expressed our results with medians and the Mann-Whitney non-parametric test was used to compare them. Since ICH volumes do not follow a linear spectrum, a logtransformation was done to make comparisons between groups. For univariate analysis, ICH volumes were also categorized according to the following cut-points: less than $30 \mathrm{~cm}^{3}, 30$ to 60 $\mathrm{cm}^{3}$, and greater than $60 \mathrm{~cm}^{3}$.

A multivariate generalized linear model was constructed to determine whether statin was an independent risk factor for greater ICH volume, after adjusting for age, vascular risk factors (diabetes, hypertension, heart disease), medication use prior to the event (antiplatelet, anticoagulant, and antihypertensive agents) and baseline INR value. P values $<0.05$ were considered significant.

\section{RESULTS}

Five hundred and thirty-nine patients were identified with a diagnosis of nontraumatic ICH (222 from Charles-LeMoyne Hospital and 317 from the CHUS). Ninety-one were excluded based on radiological confirmation of underlying lesions or suspicion of metastases in patients with known primary systemic cancer. Another 98 patients had ischemic stroke with hemorrhagic infarction and nine had blood dyscrasia with severe thrombocytopenia (platelet count less than 50,000). Eight patients were less than 18-years-old. Thirty patients were excluded because of unavailable radiological images for manual volume calculation. Those patients had their CT scan performed in another center prior to their transfer to our hospitals. Baseline characteristics of these patients were similar to the cohort included in our study.

Of 303 consecutives patients who met inclusion criteria for spontaneous ICH, 71 (23\%) were taking a statin (atorvastatin $85 \%$, simvastatin $8 \%$, pravastatin $4 \%$, others $3 \%$ ) at the time of the ICH. Statin users were significantly more likely to be younger, to present comorbidities, and to have used antiplatelet, anticoagulant, or antihypertensive agents prior to the index event (Table 1). The mean INR was not different between the two groups, although the mean INR was lower with anticoagulated statin users than with anticoagulated non-statin users $(2.27 \pm 1.04$ vs. 2.94 $\pm 2.23 ; \mathrm{p}=0.03$ ). Low-density lipoprotein levels were lower in HMG-CoA reductase inhibitors but were available in only 20 patients taking a statin and in 47 patients not using a statin. Mean baseline blood pressure was significantly higher in the non-statin group. However, within each group, Pearson correlation coefficient test shown no correlation between blood pressure and hemorrhage volume (statin $\mathrm{p}=0.1$, non-statin 
Table 1: Baseline characteristics according to presence of statin use

\begin{tabular}{|c|c|c|c|}
\hline & $\begin{array}{l}\text { Statin } \\
\mathrm{n}=71 \\
\end{array}$ & $\begin{array}{c}\begin{array}{c}\text { Non-statin } \\
\mathrm{n}=232\end{array} \\
\end{array}$ & $p$ \\
\hline Age-yr & $71.1 \pm 10.1$ & $74.9 \pm 11.5$ & 0.012 \\
\hline Male sex (\%) & $39(55)$ & $126(54)$ & 0.93 \\
\hline \multicolumn{4}{|l|}{ Risk Factors } \\
\hline diabetes mellitus (\%) & $22(31)$ & $41(18)$ & 0.016 \\
\hline hypertension (\%) & $61(86)$ & $166(72)$ & 0.015 \\
\hline heart diseases(\%) & $32(45)$ & $46(20)$ & $<0.001$ \\
\hline Prior ischemic stroke $(\%)$ & $17(24)$ & $45(19)$ & 0.41 \\
\hline Prior ICH (\%) & $4(6)$ & $14(6)$ & 1 \\
\hline \multicolumn{4}{|l|}{ Medication prior to events } \\
\hline antihypertensive (\%) & $58(82)$ & $122(53)$ & $<0.001$ \\
\hline antiplatelet (\%) & $54(76)$ & $89(38)$ & $<0.001$ \\
\hline Anticoagulant (\%) & $26(37)$ & $43(19)$ & 0.001 \\
\hline \multicolumn{4}{|l|}{ Baseline blood pressure } \\
\hline systolic & $151 \pm 18$ & $161 \pm 25$ & $<0.001$ \\
\hline diastolic & $77 \pm 10$ & $83 \pm 14$ & 0.001 \\
\hline $\mathrm{INR}$ & $1.52 \pm 0.9$ & $1.40 \pm 1.2$ & 0.45 \\
\hline anticoagulated & $2.27 \pm 1.04$ & $2.94 \pm 2.23$ & 0.03 \\
\hline non anticoagulated & $1.05 \pm 0.2$ & $1.02 \pm 0.1$ & 0.89 \\
\hline Platelet $\left(\mathrm{X} 10^{9} / \mathrm{L}\right)$ & $245 \pm 81$ & $252 \pm 95$ & 0.59 \\
\hline $\operatorname{LDL}(\mathrm{mmol} / \mathrm{L})$ & $2.47 \pm 0.25$ & $2.93 \pm 0.37$ & 0.04 \\
\hline NIHSS modified score * & $10[4,17]$ & $7[3,15]$ & 0.17 \\
\hline Glasgow coma scale * & $12[7,15]$ & $14[9,15]$ & 0.23 \\
\hline $\operatorname{MRS}<2(\%)^{\dagger}$ & $49(69)$ & $151(65)$ & 0.57 \\
\hline \multicolumn{4}{|l|}{ Time to CT scan } \\
\hline 0-6 h (\%) & $28(39)$ & $86(37)$ & \\
\hline 6-24 h (\%) & $5(7)$ & $30(13)$ & 168 \\
\hline$>24 \mathrm{~h}(\%)$ & $17(24)$ & $52(22)$ & \\
\hline Unknown delay (\%) & $21(30)$ & $64(28)$ & \\
\hline \multicolumn{4}{|l|}{ ICH location } \\
\hline Left hemisphere (\%) & $38(53.5)$ & $104(44.8)$ & 0.22 \\
\hline Lobar (\%) & $39(54.9)$ & $104(44.8)$ & \\
\hline Basal Ganglia (\%) & $24(33.8)$ & $100(43.1)$ & 0.329 \\
\hline Infratentorial $(\%)$ & $8(11.3)$ & $28(12.1)$ & \\
\hline Ventricular extension (\%) & $29(41)$ & $102(44)$ & 0.64 \\
\hline
\end{tabular}

ICH indicates intracerebral hemorrhage. MRS indicates modified Rankin Scale.*Continuous variables are showed as mean and mNIHSS and Glascow coma scale are displayed as median [25th percentile, 75 th percentile]. $\dagger$ MRS prior to ICH.

$\mathrm{p}=0.3$ ). Otherwise, baseline characteristics were similar between groups.

Pre-ICH statin use was associated with a significantly higher median hemorrhage volume $(31.2[10,82.1] \mathrm{ml}$ vs $16[4,43.8]$ $\mathrm{ml}$ in those not taking statin; $\mathrm{p}=0.006$ ) (Table 2 ). The volumes were expressed in term of medians because of the asymmetric volume distribution in each group. However, mean volumes were also different $(51.5 \pm 55.8 \mathrm{ml}$, compared to $35.2 \pm 45.4 \mathrm{ml}$; $\mathrm{p}=0.027)$. This difference remained significant $(\mathrm{p}=0.03)$ when we stratified ICH into volume categories. Volume less then $30 \mathrm{ml}$ was present in $49 \%$ of statin users vs $66 \%$ of non-statin users while $34 \%$ and $20 \%$ respectively had volume $>60 \mathrm{ml}$. No difference was seen according to the type of statin used. After adjusting for anticoagulant, antiplatelet, antihypertensive medication, INR, platelets, baseline blood pressure, ICH location and other risk factors (age, diabetes, hypertension, ischemic heart disease) in the multivariate analysis, HMG-CoA reductase inhibitors remained associated with an increased baseline ICH volume ( $\mathrm{p}=0.007)$. The other independent variable associated with an increased ICH volume was antiplatelet medication (median ICH volume of $26.3 \mathrm{ml}$ in those taking antiplatelet agents vs $16.4 \mathrm{ml}$ in those not taking antiplatelet agents; $\mathrm{p}=0.025)$. The inter-rater reliability for $\mathrm{ICH}$ volume measurement was excellent for the $25 \mathrm{CT}$ scans reviewed by both JMB and GR (Lin's correlation coefficient 0.98).

The baseline ICH volume was higher in statin users in all "time to CT" subgroups (Table 2) except in the 6-24 hour subgroups for which the number of patients using statin was very small ${ }^{5}$. The median baseline ICH was increased for lobar and infratentorial cases but it did not reach statistical significance for basal ganglia ICH.

A follow-up CT was obtained in 29 (41\%) statin patients and in $100(43 \%)$ non-statin patients. Again, the delay between the baseline CT and the first follow up CT scans was not different among groups and two thirds of follow up CT scans were done within 72 hours. The main reasons for the absence of a follow up CT scan were early mortality $(50.5 \%)$, mild symptoms $(19 \%)$, futility due to severe baseline disability or comorbidities $(8.9 \%)$ and unspecified (21.6\%). Statin users who did not have a control CT scan had significant higher mean initial ICH volume (71.1 \pm 62.6 vs $23.2 \pm 25.2 ; \mathrm{p}<0.001)$, a higher mNHISS score $(12.9 \pm 7.5$ vs $7.96 \pm 6.2 ; \mathrm{p}=0.001)$ and a lower Glasgow coma scale $(9.7 \pm 4.2$ vs $12.9 \pm 2.9 ; \mathrm{p}=0.01)$ compared to those with a follow up CT scan. Non-statin users without a control CT scan were more likely to have a higher mean initial volume ICH (43.5 \pm 54.2 vs $24.3 \pm 26.5 ; \mathrm{p}<0.001)$ and to be older $(76.9 \pm 10.7$ vs $72.3 \pm 12 ; \mathrm{p}=0.002$ ) than non-statin users with follow up brain imaging. Other characteristics between patient with or without a control CT scan were similar.

One patient in the statin group and 13 patients in the nonstatin group had craniotomy for hematoma evacuation after the baseline CT scan. Therefore, the median ICH volume on the follow up CT scan and the mean variation of $\mathrm{ICH}$ volume between the baseline CT and second CT were calculated for 28 statin users and 87 non-statin users. No difference was observed for the median ICH volume on the follow up CT $(13.6$ [4.2, 41.8] $\mathrm{ml}$ in statin users vs. $12.1[3.1,31.5] \mathrm{ml}$ in non statin users; $\mathrm{p}=$ 0.5 ) (Table 3). When means were compared instead of medians for the follow up CT, a trend toward higher mean $\mathrm{ICH}$ volume among statin users was observed $(33.6 \pm 47.5 \mathrm{ml}$ vs. $21.2 \pm 25.2$ $\mathrm{ml} ; \mathrm{p}=0.076)$. A significant increase in mean ICH volume progression between baseline and first follow up CT scans was also present in HMG-CoA reductase users compared to others. $(+10.8 \pm 31.2 \mathrm{ml} \mathrm{vs} .+0.9 \pm 15.9 \mathrm{ml} ; \mathrm{p}=0.03 ; 95 \%$ CI: $[-1,+22.6]$ $[-2.5,+4.3])$. 
Table 2: Hemorrhage volume and location on baseline CTscan

\begin{tabular}{|c|c|c|c|}
\hline & $\begin{array}{l}\text { Statin } \\
\mathrm{n}=71 \\
\end{array}$ & $\begin{array}{c}\begin{array}{c}\text { Non-Statin } \\
\mathrm{n}=232\end{array} \\
\end{array}$ & ${ }^{p}$ \\
\hline $\begin{array}{l}\text { Median baseline ICH volume } \\
(\mathrm{ml})^{*}\end{array}$ & $31.2[10,82.1]$ & $16[4,43.8]$ & 0.006 \\
\hline \multicolumn{4}{|c|}{$\begin{array}{l}\text { Median baseline ICH volume (ml) vs } \\
\text { time to CT scan }\end{array}$} \\
\hline $0-6 \mathrm{~h}$ & $64.3[15,105]$ & $21.9[6,62]$ & 0.048 \\
\hline 6-24h & $4.5[1,21]$ & $26.2[7,56]$ & 0.1 \\
\hline$>24 \mathrm{~h}$ & $16.8[10,28]$ & $11.9[3,26]$ & 0.3 \\
\hline Unknown delay & $43.3[17,99]$ & $12.3[4,46]$ & 0.009 \\
\hline \multicolumn{4}{|c|}{$\begin{array}{l}\text { Median baseline ICH volume (ml) vs } \\
\text { ICH location }\end{array}$} \\
\hline Lobar & $57.6[21.4,107]$ & $28.8[11.7,67.3]$ & 0.02 \\
\hline Basal Ganglia & $10.0[2.6,33.6]$ & $8.3[1.9,33.8]$ & 0.973 \\
\hline Infratentorial & $33.2[7.3,47.8]$ & $9.9[2.5,22.2]$ & 0.016 \\
\hline
\end{tabular}

*All ICH volume are displayed as median [25th percentile, 75 th percentile].

Finally, the death rate during hospitalization (mean of 16 days) was similar in those exposed and those not exposed to statin ( $45 \%$ vs. $38 \% ; \mathrm{p}=0.31$ ). This also held true for the percentage of deaths directly related to ICH $(88 \%$ of deaths in each group; $p=0.9$ ). Other etiologies of death were related to infection, pulmonary embolism, and ischemic heart disease. Only $16(23 \%)$ statin users and $55(24 \%)$ non-statin users were discharged home after their hospitalization $(\mathrm{p}=0.8)$.

\section{Discussion}

We found a significant increase in the median ICH volume on the baseline CT scan of statin users compared to non-statin users presenting with a spontaneous ICH. This remained significant after adjustments for other medical comorbidities and treatment. This study also showed a significant increased mean ICH volume progression between the first and second $\mathrm{CT}$ scans in patients treated with statins. To our knowledge, no research has been conducted to determine the potential effects of statin therapy on initial hematoma volume and on ICH volume expansion between baseline and follow-up CT scans in spontaneous ICH.

Our observations are consistent with the report of a recent clinical trial on high-dose statin therapy. ${ }^{13}$ An exploratory analysis of the SPARCL trial focusing on the 88 patients who experienced ICH while enrolled in the study raised concern about an association between HMG-CoA reductase inhibitors and a significant increase in hemorrhage risk. ${ }^{7}$

One possible explanation relates to statin's cholesterollowering effect. In an autopsy supported study, there was evidence that hypocholesterolemia may lead to the rupture of small intraparenchymal cerebral arteries by weakening arterial walls. ${ }^{14}$ Other epidemiologic studies also demonstrated that low-
Table 3: Hemorrhage volume and volume variation in patients with follow-up CT scan

\begin{tabular}{|c|c|c|c|}
\hline & $\begin{array}{l}\text { Statin } \\
\mathrm{n}=28\end{array}$ & $\begin{array}{c}\text { Non-Statin } \\
\mathrm{n}=87\end{array}$ & $p$ \\
\hline \multicolumn{4}{|l|}{ Median ICH volume $m l$} \\
\hline Baseline CT scan & $13.8[3.9,35.5]$ & $11.3[3.8,29.3]$ & 0.7 \\
\hline Follow-up CT scan & $13.6[4.2,41.8]$ & $12.1[3.1,31.5]$ & 0.5 \\
\hline \multicolumn{4}{|l|}{$\begin{array}{l}\text { Median ICH volume on follow up CT scan } \\
\text { vs delay between CT scans. (\% of patient) }\end{array}$} \\
\hline $0-6$ hours & $62(4)$ & $\begin{array}{l}50.8[22,92] \\
\text { (3) }\end{array}$ & 1 \\
\hline 6-24 hours & $\begin{array}{l}15.8[11,93] \\
(14)\end{array}$ & $\begin{array}{c}5.6[1,13] \\
(14)\end{array}$ & 0.06 \\
\hline $24-48$ hours & $\underset{(32)}{10.7[3,19]}$ & $\begin{array}{c}7.9[4,25] \\
(22)\end{array}$ & 0.7 \\
\hline 48-72 hours & $\begin{array}{c}2.3[0.1,33] \\
(11)\end{array}$ & $\begin{array}{l}17.7[4,38] \\
\quad(22)\end{array}$ & 0.2 \\
\hline$>72$ hours & ${ }_{(39)}^{12.5[4,97]}$ & $\begin{array}{c}12.3[4,30] \\
\quad(39)\end{array}$ & 0.4 \\
\hline $\begin{array}{l}\text { Mean variation ICH volume (ml) between } \\
\text { baseline and first follow up CT scans }\end{array}$ & $+10.8 \pm 31.2$ & $+0.9 \pm 15.9$ & 0.03 \\
\hline $95 \% \mathrm{CI}$ & $-1,+22.6$ & $-2.5,+4.3$ & \\
\hline
\end{tabular}

Continuous variables displayed as mean $\pm \mathrm{SD}$, or median [25th percentile, 75 th percentile]. ICH indicates intracerebral hemorrhage. $95 \%$ $\mathrm{CI}$ indicates $95 \%$ confidence interval.

density lipoprotein (LDL) cholesterol levels were inversely associated with primary ICH risk. ${ }^{1-3}$ Similarly, Bang et al's retrospective study reported a relationship between recanalization therapy, low cholesterol, and hemorrhagic infarction ${ }^{15}$ while low LDL levels were reported by some as associated with hemorrhagic transformation after large artery stroke ${ }^{16}$ or increased mortality in ICH. ${ }^{17}$ The investigators in the SPARCL trial, however, found no relationship between ICH risk and low-density lipoprotein or total cholesterol levels. ${ }^{13}$ The mechanism by which statin increases ICH risk could also be independent of its lipid-lowering effect and may be related to its pleiotropic and antithrombotic properties. Statin agents have been reported to selectively inhibit platelet G-coupled, $\alpha$ thrombin protease-activated receptors (PAR-1), which are cellbound proteins that link platelet activation and thrombin formation. ${ }^{5}$ In addition, statins might directly influence platelet membrane, resulting in decreased function. ${ }^{4}$

Despite increased mean hematoma volume in statin users, we did not detect a difference of mortality between the two groups. Experimental models of ICH in rats showed improvement in neurological outcome after administration of low-dose atorvastatin..$^{18}$ The potential benefits of statin therapy for human ICH was also described in a recent study in which it was associated with reduced 30-day mortality, but not improved functional outcome. ${ }^{19}$ Conflicting results are otherwise found in the literature. The NASIS study showed a reduction of mortality and neurological disability with statin use ${ }^{20}$ while FitzMaurice et al failed to reproduce this relationship. ${ }^{21}$ In one of FitzMaurice 
et al's analyses, pre-ICH statin use was associated with an interesting but nonsignificant $19 \%$ increase in initial hemorrhage volume. HMG-CoA reductase inhibitors were also associated with a higher frequency of ICH after intra-arterial thrombolysis but without any impact on outcome.22 All these observations about mortality are consistent with ours and the SPARCL subgroup analysis, in which no difference was demonstrated in the rate of fatal hemorrhagic strokes with statin agents. ${ }^{7}$

We also showed that the increase in ICH volume among statin users was significant in lobar and infratentorial ICH but not in basal ganglia ICH. Since the number of infratentorial cases was small it is possible that the influence of statins on ICH may be more important in those with underlying amyloid angiopathy than in those with "pure" hypertensive ICH but this deserves further consideration.

Our study has a number of limitations, most of them due to its retrospective nature. First, we had to exclude 30 cases because of unavailable CT data (patients transferred from other centers). It is possible that this may have introduced a bias but this seems very unlikely considering that the baseline characteristics of these patients were similar to cases included in the analysis. Also, LDL, HDL and total cholesterol levels were not systematically assessed upon admission since this was a retrospective study and cholesterol levels are not routinely done in ICH patients. Furthermore, we do not have reliable information about statins dose and duration of therapy prior to the event and it was impossible to analyze the dose response effect of statins on ICH volume and impossible to differentiate if the increase ICH volume was secondary to the statins LDL lowering property or their pleiotropic effects. There were also important confidence interval overlaps between baseline and follow up ICH volume between statin and non-statin users. Because the study was retrospective it is also difficult to draw conclusions regarding the relation between the ICH volume and time to CT. Nevertheless, a trend for higher ICH volume was seen in statin users for all "time to CT" subgroups except for the 6-24 hours subgroups but the number of patients in this group was very small, precluding any reliable conclusions. The significant increase in ICH volume between baseline and follow up CT scans in statin users should also be interpreted with caution because of the relatively small number of follow up CT scans. Furthermore, the increase in ICH volume was only significant when means were compared and not medians, thus probably indicating that a few patients were responsible for the increase in ICH volume. Although baseline characteristics were similar in many regards for patients with and without follow up imaging, those with control CT scan had smaller ICH volumes, lower mNIHSS score, better Glasgow coma scale and were younger. In summary, these patients had a more benign profile than those without a second CT scan. It is possible that we underestimated the effect of statins on ICH volume progression. Selection biases are inherent to retrospective studies. Therefore our findings on ICH volume progression need further confirmation and conclusions would be premature at this point.

\section{Conclusions}

Our results suggest that statin use prior to ICH is associated with higher hematoma volume and may contribute to hemorrhage volume progression. Statin benefits in reducing the overall risk of ischemic stroke and coronary heart disease is supported by numerous randomized controlled trials and metaanalyses ${ }^{9,13}$ and we would certainly not recommend withdrawing statins in patients at risk of ischemic events but caution is warranted in those with prior $\mathrm{ICH} .{ }^{23}$ Given the widespread use of HMG-CoA reductase inhibitors and in light of the conflicting results available regarding the effects of statins in $\mathrm{ICH}$, a larger prospective study of how statins pretreatment, upholding, and withdrawal may influence initial ICH volume and variation in hematoma volume is warranted.

\section{ACKNOWLEDGEMENTS}

The authors thank Martine Mainville, Jean Rivest, and Léo Berger.

\section{REFERENCES}

1. Yano K, Reed DM, MacLean CJ. Serum cholesterol and hemorrhagic stroke in the Honolulu heart program. Stroke. 1989; 20:1460-5.

2. Zhang X, Patel A, Horibe H, et al. Cholesterol, coronary heart disease, and stroke in the Asia Pacific region. Int J Epidemiol. 2003;32:563-72.

3. Iso H, Jacobs DR Jr., Wentworth D, et al. Serum cholesterol levels and six-year mortality from stroke in 350,977 men screened for the multiple risk factor intervention trial. N Engl J Med. 1989; 320:904-10.

4. Mosheimer BA, Kaneider NC, Feistritzer C, et al. Cd40-liganddependent induction of cox-2 gene expression in endothelial cells by activated platelets: Inhibitory effects of atorvastatin. Blood Coagul Fibrinolysis. 2005;16:105-10.

5. Serebruany VL, Miller M, Pokov AN, et al. Effect of statins on platelet par-1 thrombin receptor in patients with the metabolic syndrome (from the par-1 inhibition by statins [Paris] study). Am J Cardiol. 2006;97:1332-6.

6. Kahn ML, Nakanishi-Matsui M, Shapiro MJ, et al. Proteaseactivated receptors 1 and 4 mediate activation of human platelets by thrombin. J Clin Invest. 1999;103:879-88.

7. Goldstein LB, Amarenco P, Szarek M, et al. Hemorrhagic stroke in the stroke prevention by aggressive reduction in cholesterol levels study. Neurology. 2008;70:2364-70.

8. Collins R, Armitage J, Parish S, et al. Effects of cholesterollowering with simvastatin on stroke and other major vascular events in 20536 people with cerebrovascular disease or other high-risk conditions. Lancet. 2004;363:757-67.

9. Vergouwen MD, de Haan RJ, Vermeulen M, et al. Statin treatment and the occurrence of hemorrhagic stroke in patients with a history of cerebrovascular disease.[see comment]. Stroke. 2008; 39:497-502.

10. Baigent C, Keech A, Kearney PM, et al. Efficacy and safety of cholesterol-lowering treatment: Prospective meta-analysis of data from 90,056 participants in 14 randomised trials of statins. Lancet. 2005;366:1267-78.

11. Kasner SE, Cucchiara BL, McGarvey ML, et al. Modified National Institutes of Health Stroke Scale can be estimated from medical records. Stroke. 2003;34:568-70.

12. Kothari RU, Brott T, Broderick JP, et al. The ABCs of measuring intracerebral hemorrhage volumes. Stroke. 1996;27:1304-5.

13. Amarenco P, Bogousslavsky J, Callahan A 3rd, et al. High-dose atorvastatin after stroke or transient ischemic attack. N Engl J Med. 2006;355:549-59.

14. Reed DM. The paradox of high risk of stroke in populations with low risk of coronary heart disease. Am J Epidemiol. 1990;131: 579-88.

15. Bang OY, Saver JL, Liebeskind DS, et al. Cholesterol level and symptomatic hemorrhagic transformation after ischemic stroke thrombolysis. Neurology. 2007;68:737-42. 
16. Kim BJ, Lee SH, Ryu WS, et al. Low level of low-density lipoprotein cholesterol increases hemorrhagic transformation in large artery atherothrombosis but not in cardioembolism. Stroke. 2009; 40:1627-32.

17. Ramirez-Moreno JM, Casado-Naranjo I, Portilla JC, et al. Serum cholesterol LDL and 90-day mortality in patients with intracerebral hemorrhage. Stroke. 2009;40:1917-20.

18. Seyfried D, Han Y, Lu D, et al. Improvement in neurological outcome after administration of atorvastatin following experimental intracerebral hemorrhage in rats. J Neurosurg. 2004:101:104-7.

19. Naval NS, Abdelhak TA, Zeballos P, et al. Prior statin use reduces mortality in intracerebral hemorrhage. [see comment]. Neurocrit Care. 2008;8:6-12
20. Leker RR, Khoury ST, Rafaeli G, et al. Prior use of statins improves outcome in patients with intracerebral hemorrhage. Prospective data from the national acute stroke Israeli surveys (NASIS). Stroke. 2009;40:2581-4.

21. FitzMaurice E, Wendell L, Snider R, et al. Effect of statins on intracerebral hemorrhage outcome and recurrence. Stroke. 2008; 39:2151-4.

22. Meier N, Nedeltchev K, Brekenfeld C, et al. Prior statin use, intracranial hemorrhage, and outcome after intra-arterial thrombolysis for acute ischemic stroke. Stroke. 2009;40: 1729-37.

23. Amarenco P, Labreuch J. Lipid management in the prevention of stroke: review and updated meta-analysis of statins for stroke prevention. Lancet Neurol. 2009;8;453-63. 